


Tendências regalistas e episcopalistas em bibliotecas de Coimbra do séc. XVIII

Autor(es): Rodrigues, Manuel Augusto

Publicado por: Imprensa da Universidade de Coimbra

URL persistente:

URI:http://hdl.handle.net/10316.2/43777

DOI:

DOI:https://doi.org/10.14195/2183-8925_10_18

Accessed : $\quad$ 26-Apr-2023 15:50:05

A navegação consulta e descarregamento dos títulos inseridos nas Bibliotecas Digitais UC Digitalis, UC Pombalina e UC Impactum, pressupõem a aceitação plena e sem reservas dos Termos e Condições de Uso destas Bibliotecas Digitais, disponíveis em https://digitalis.uc.pt/pt-pt/termos.

Conforme exposto nos referidos Termos e Condições de Uso, o descarregamento de títulos de acesso restrito requer uma licença válida de autorização devendo o utilizador aceder ao(s) documento(s) a partir de um endereço de IP da instituição detentora da supramencionada licença.

Ao utilizador é apenas permitido o descarregamento para uso pessoal, pelo que o emprego do(s) título(s) descarregado(s) para outro fim, designadamente comercial, carece de autorização do respetivo autor ou editor da obra.

Na medida em que todas as obras da UC Digitalis se encontram protegidas pelo Código do Direito de Autor e Direitos Conexos e demais legislação aplicável, toda a cópia, parcial ou total, deste documento, nos casos em que é legalmente admitida, deverá conter ou fazer-se acompanhar por este aviso. 
REVISTA DE HISTORIA DAS IDEIAS IO


INSTITUTO DE HISTÖRIA E TEORIA DAS IDEIAS FACULDADE DE LETRAS 
MANUEL AUGUSTO RODRIGUES *

\section{TENDENCIAS REGALISTAS E EPISCOPALISTAS EM BIBLIOTECAS DE COIMBRA DO SÉC. XVIII}

Duas personalidades que exerceram bastante influência na evolução do pensamento jurídico canónico em Portugal do séc. XVIII foram Zeger-Bernard van Espen (1646-1728) e Iohann Nikolaus von Hontheim (1701-90). E isso verificou-se particularmente na Universidade de Coimbra.

Basta percorrer o Compêndio Histórico do Estado da Universidade de 1771, os Estatutos Pombalinos de 1772, o Diário de Fr. Manuel do Cenáculo, a obra de António Pereira de Figueiredo, os compêndios adoptados nas Faculdades de Cânones e Leis e as teses nelas defendidas - para logo nos apercebermos do papel exercido pelo Ius Ecclesiasticum de Van Espen e pelo De Statu Ecclesiae et Status de Febrónio na formação da inteligência jurídico-canónica dos portugueses.

E certo que ao lado desses dois mestres não podemos deixar de colocar outros nomes: Claude Fleury, Bochmero, Riegger, Heinécio, Carlos Antonio Martini e outros, todos eles defensores tenazes dos ideais jansenistas e regalistas e jusnaturalistas ou absolutistas.

As críticas contundentes feitas pelo núncio Bartolomeu Pacca à Universidade de Coimbra e ao seu reitor D. Francisco de Lemos de Faria Pereira Coutinho, em cartas enviadas para Roma, testemunham claramente os novos rumos que a Universidade tomara no campo da jurisprudência $\left(^{(}\right)$.

A existência de várias das obras daqueles autores na biblioteca de D. Francisco de Lemos e na do Colégio de S. Tomás revela o interesse que elas despertavam entre nós.

* Faculdade de Letras da Universidade de Coimbra.

(1) Vid. Samuel J. Miller, Portugal and Rome c. 1748-1830. An Aspect of the Catholic Englightenment, Roma, 1978. 


\section{Revista de História das Ideias}

Van Espen nasceu em Lovaina em 1646. Aí estudou e leccionou, sfguindo desde o início as linhas mestras dos melhores regalistas, como Pierre Pithou, autor de Liberté de l'Église Gallicane (1594); Edmund Richer, autor de De ecclesiastica et politica potestate; Pierre et Jacques Dupuy, autor de Des Droits €t libertés de l'Église Gallicane avec les preuves; e Pierre de Marca, autor do De concordia sacerdotii et imperii de libertatibus Ecclesiae Gallicane $\left(^{2}\right)$.

No fundo tcdos defendiam que o poder legislativo absoluto não pertence ao papa mas à hierarquia da Igreja em geral; negavam o poder temporal da Igreja e apregoavam o episcopalismo.

A obra fundamental de Van Espen é o Ius Ecclesiasticum Universum (1700), elaborada segundo o modelo das Institutiones de Justiniano. Outros canonistas do seu tempo, como Fagnanno ( $(† 1678)$, Pirhing (†1679), Schmalzgrueber (†1753) e Reiffenstuel $(\dagger 1737)$, cujas obras encontramos na biblioteca de D. Francisco de Lemos, ficaram relegadas para um plano secundário com o aparecimento do Ius Ecclesiasticum de Van Espen, o qual se impôs por toda a Europa $\left({ }^{3}\right)$.

Segundo F. Claeys Bouaert, foi o primeiro livro a abandonar a ordem das Decretais para se inspirar na divisão baseada no objecto das leis: De personis, De sacramentis, De beneficiis e De judicibus, delictis et poenis. Entre os autores citados, conta-se o português Agostinho Barbosa.

Van Espen recorre às fontes do direito segundo o programa estabelecido nos prologómenos e manifesta uma predilecção particular pelos jurisconsultos belgas e, sobretudo, franceses.

(2) Ehrenreich Pirhing, S.J. (1606-79), Canonista, foi professor em Ingolstadt, a partir de 1636, de Filosofia e Teologia Moral; e em Dillingen de Direito Canónico e Exegese a partir de 1643; entre 1653 e 1656 foi reitor em Eichstätt. A obra Ius Canonicum in $V$ libros Decretalium distributum, 5 vols., Dillingen, 1674-78, V 1693, deu-lhe grande reputação. - Anacleto Reiffenstuel, O.F.M. (1642-1703) leccionou em Freising. Foi grande comentador das Decretais e escreveu Ius Canonicum Universium, 5 vols. Freising, 1700-14; é autor ainda de outras obras. - Franz Xaver Schmalzgrueber, S.J. (1663-1735), foi professor de Direito Canónico em Dillingen e Ingolstadt e chanceler da Universidade. - Prospero Fagnani Boni (158-1678) leccionou na Sapienza de Roma e exerceu vários cargos na cúria pontifícia. Redigiu a bula «Aeterni Patris» de Gregório XV, de 15 de Novembro de 1621, sobre a eleição do papa. A sua obra Ius Cononicum sibe commentaria absolutissima in $V$ libros Decretalium (5 vols., Roma, pp. 1661 e ss.) "bezeugt die Rechtentwicklung nach dem Tridentinum u. trug ihm die Bezeichnung» Doctor Caecus oculatissimus ein».

(3) Sobre Van Espen, vid. Gustave Leclerc, S.D.B., Zeger-Bernard Van Espen et l'autorité ecclésiastique, Zurique, 1964. 


\section{Bibliotecas de Coimbra do Séc. XVIII}

Há autores que dizem ter Van Espen seguido, sem o citar, o célebre autor Louis Thomassin, que escreveu Ancienne et nouvelle discipline de l'Église touchant les bénéfices et les bénéficiers.

Também se serve bastante de Pierre de Marca, Charles Févret, Charles Dumoulin, Pierre Stockman e Pierre Dupuy.

A doutrina de Van Espen abrange em síntese os seguintes pontos: a jurisdição eclesiástica é espiritual; a distinção dos dois poderes, o temporal e o espiritual, é fundamental; a Igreja deve excluir radicalmente a esfera do temporal; o poder da Igreja é puramente ministerial; o poder legislativo pertence a toda a Igreja e não apenas ao pontífice; o príncipe tem o direito de exercer o «placet» para bem da sociedade.

Van Espen escreveu ainda outras obras que tiveram várias є.dições um pouco por toda a parte.

A sua influência foi enorme: na Bélgica e na antiga Universidade de Lovaina, na Alemanha e Âustria, na Itália, na Espanha e Portugal, etc. $\left({ }^{4}\right)$.

Sob o reinado da imperatriz Maria Teresa (1740-80) e do imperador José II, Viena tornou-se um foco importante de irradiação de ideias regalistas, tendo o chanceler Kaunitz e, em especial, Van Swieten contribuído largamente para a reforma dos estudos e para a divulgação de Van Espen, inclusivamente.

Em Lovaina o professor de Direito Josse Le Plat (1732-1810), fervoroso promotor do josefismo, encarregou-se de reeditar Van Espen e Riegger (1705-75).

Van Swieten, ardoroso jansenista e defensor da Igreja de Utrecht, foi chamado em 1744 para a corte de Viena, onde viria a adquirir extraordinária influência. Foi director de estudos e presidente da comissão de censura dos Estados hereditários. De acordo com Bartolomeu de Bellegarde, muito contribuiu para desenvolver em Viena e no país as ideias de Arnauld, Nicole, Quesnel, Opstraet e Van Espen.

Também em Espanha e Portugal foi grande a influência de Van Espen. Camponanes e Jovellanos Ramires em Espanha e, entre nós, António Pereira de Figueiredo foram os mais importantes. Em 18 de Maio de 1819 o núncio em Madrid, escrevendo para Roma, louva o zelo do inquisidor geral Y Castillon, arcebispo de Tarragona, porque «este proscreveu as obras de Van

(4) Edições do Ius Ecclesiasticum (16): Lovaina 1700, 1712, 1721, 1753; Colónia 1702. 1708, 1715, 1729, 1777: Paris 1721; Lovaina - Bruxelas - Paris 1768; Mogúncia 1789, 1791; Veneza 1721, 1769. 1781.

Opera omnia (18): Lovaina 1700, 1732. 1759, 1778; Paris 1753; Colónia 1702, 1708, 1729, 1748, 1777-78; Ruão 1721; Veneza 1732. 1769, 1770, 1786, 1788; Nápoles 1766-70, 1771. 
Espen, Cavallaro e a teologia dita de Lião das Universidades e por se aplicar a destruir os traços deixados depois de meio-século pelo jansenismo». Pereira de Figueiredo chama a Van Espen o canonista belga mais sábio.

Acerca de Van Espen escreveu Martin Grabmann:

«Namentlich die beiden letzten (Franz Schmalzgrueber u. Anaklet Reiffenstuel) stehenzwar teilweise and Erudition wie auch an Eleganz den Löwener Kanonisten u. einflussreichen Vertreter des Episkopalismus u. Gallikanismus Z. B. Van Espen nach, übertreffen ihn aber um so mehr durch Solidität der Doktrin (Scheeben im Katholik 1867, I, 162) (5).

E Joannes Devoti diz:

"Sed illa ecclesiasticae eruditionis cum ipsa juris praescriptione consociatio quam ille habet, fecit, ut ejus opus praeferendum videtur operibus Fagnani, Leurenu, Pirhing, Analeti Schmalzgrueberu, ceterorum similum, qui licet ecclesiasticas leges multo verius, diligentius, accuratius Van Espenio interpretati sint, tamen nihil de rerum originibus et antiquitatibus investigandis laborarunt, et in multis riculos consectari, quam eadem ex fontibus haurire maluerunt» $\left({ }^{(}\right)$.

O episcopalismo na Alemanha teve em Johan Nikolaus von Hontheim (1701-90), que usaria o pseudónimo de Justino Febrónio, o seu expoente máximo. Foi discípulo de Van Espen e tentou sprofundar o tema da constituição eclesiástica. A obra principal é o de Statu Ecclesiae et Legitima Potestate Romani Pontificis Liber Singularia ad reumiendos dissidentes in religione Christiara compositus, 4 ts. em 5 vols. (Francoforte 1763-73). Nele se contêm os princípios basilares do episcopalismo e do regalismo mas com particular atenção para a condição alemã $\left({ }^{7}\right)$.

Em especial, nele se defendem os seguintes pontos: para recuperar os cristãos divididos na fé é necessário antes de mais reconduzir a Igreja à sua constituição originária da antiguidade cristã. Devem ser restituídos aos bispos e aos concílios os direitos que lhes foram tirados e serem precisados os limites do primado romano. O papa não é infalível e não possui um poder monárquico ilimitado sobre a Igreja. Esse poder reside, antes, na totalidade dos bispos ou no concílio ecuménico.

(5) Martin Grabmann, Geschichte der Katholischien Theologie, Friburgo, 1933, p. 184.

(8) Joannes Devoti, Ius Caninicum universum, publicum et privatum. t. I, Roma. 1837, Praefatio, p. V e VI.

(7) Sobre Hontheim, vid.: Dictionnaire de Théologie Catholique. V, 2115-2124; Catholicisme, IV, 1129 s., V 933; Lexikon für Theologie und Kirche V, 479-80. 
As decisões e as leis disciplinares emanadas do papa tornam-se obrigatórias só mediante aprovação explícita ou implícita da igreja universal e a sua aceitação nas igrejas nacionais e nas dioceses.

Ao sucessor de Pedro pertence apenas uma preeminência honorífica a respeito dos bispos (primatus honoris).

De forma essencial e necessária encontram-se nele apenas os direitos respeitantes à obrigação de vigiar sobre a observância dos cânones e a preservação da fé e, em geral, sobre a unidade e concórdia da Igreja (primatus inspectionis et directionis).

Todos os outros direitos não essenciais que foram indevidamente atribuídos à cúria depois da falsificação pseudoisidoriana \& sua consequente evolução - como em particular a confirmação ๔ deposição dos bispos, a nomeação para cargos eclesiásticos noutras dioceses, as reservas, as dispensas e as isenções papais, etc. - são direitos que devem ser restituídos ao episcopado que, em caso de necessidade, pode também voltar a apropriar-se deles.

Como meios de luta de afirmação destes direitos recomendam-se: acções propagandísticas, um concílio ecuménico livre, sínodos provinciais e nacionais, acção unitária dos bispos unidos aos soberanos, uso do "placet» e da "Appelatio ad abusu», etc.

Foi grande a difusão da obra e do pensamento de Febrónio.

Apesar de Clemente XIII ter colccado no Index dos Livros Proibidos o livro de Febrónio e de ter solicitado aos bispos alemães que procedessem energicamente contra ele, todavia os arcebispos de Colónia, e Mogúncia redigiram em Coblença scb a presidência de Febrónio um memorandum de 31 artigos ( «Avisamenta»), concebido substancialmente segundo o espírito febroniano.

Nessas circunstâncias Febrónio, que tinha oficialmente r.egado ser o autor do livro, refutou a retratação exigida. Só quando o arcebispo de Treviri, o eleitor Clemente Venceslau, sob pressão da cúria romana, o rejeitou é que Febrónio se decidiu enviar a Roma tal retratação (1778).

O Commentarium in suam retractationem (que ele publicou em 1781) demonstra contudo que as suas ideias se tinham mantido inalteradas.

As Notícias Eclesiásticas de 5 de Junho de 1771 para servir de suplemento à obra de Justino Febrónio contêm uma defesa forte e vigorosa do livro De Statu Ecclesiae. A certa altura, diz-se que a Corte de Portugal «não se satisfazendo com dar muitos elogios a esta obra de Febrónio e de a vindicar das censuras com que alguns espíritos turbulentos tinham procurado deslustrá-la a fez traduzir e imprimir em português». 
Nestas informações disserta-se largamente sobre a boa aceitação que o livro encontrou por toda a Europa e faz-se uma apologia clara do seu mérito.

«Discutindo estas últimas alegações Febrónio ou os seus apologetas, observam que se hoje não se devem recear os mesmos efeitos do ultramontanismo que em outro tempo causaram turbações tão tristes e guerras tão escandalosas na cristandade é porque os príncipes e os povos estão hoje mais ilustrados e mais vigilantes sobre estas matéria e que, ainda quando a Corte de Roma quisesse, ela não podia conseguir iguais empresas às de Gregório VII, Bonifácio VIII, etc. mas que esta Corte nada tem perdido de seu antigo sistema; e que os seus novos escritores, ainda o mesmo Bento XIV, apesar dos seus superiores talentos e do seu espírito de moderação, sustentaram estas falsas máximas sem rebaterem coisa alguma delas».

A biblioteca do Bispo de Coimbra e Reformador-Reitor da Universidade D. Francisco de Lemos de Faria Pereira Coutinho era bastante rica e diversificada. Ao tcdo possuía 1430 obras, sendo 180 de Direito e Disciplina Eclesiástica, 38 de Documentos Pastorais e 125 de Direito. Os melhores autores estavam nela representados. Aqui apenas referiremos algumas das obras que manifestam tendências jansenistas, regalistas e episcopalistas.

Zeger-Bernard van Espen (1646-1728) figura com o seu Jus Ecclesiasticum (Lovaina, 1778); com os Scholia in Canones Conciliorum (Colónia, 1728); e com o Supplementum aos mesmos (Veneza, 1769). Enrico Pirhing com o Jus Canonicum (Dillingen, 1722). Anacletus Reiffenstuel com Jus Canonicum Universum (Veneza, 1735). Rochmero com Jus Ecclesiasticum (Halle, 1756). Justinus Febrónio com o De Statu Ecclesiae (Lucca 1768; Bullioni (Francoforte) 1763-1765). Louis Thomassin com o Traité dec Edits et des Autres Moyens Spirituels et Temporels (Paris, 1703); e com Ancienne et Nouvelle Discipline de l'Église touchant les Bénéfices et les Bénéficiers (Paris, 1702). Joannes Cabassout com a Theoria et Praxis Iuris Canonici (Lião, 1691). Paulo Joseph Rieger com as Institutiones Jurisprudentias Ecclesiasticae (Coimbra, 1785), e com Corpus Iuris Canonici (Viena, 1757). Francisco Schmalzgrueber com os Consilia Iuris (Dillingen 1740); com Clerus Secularis et Regularis (ibid. 1726); Succinta SS. Canonum Doctrina (Nápoles 1738); e com Ius Ecclesiasticum Universum (ibid., 1738). Joannes Baptista Pitton com várias cbras. Joannes Gittlieb Heinécio com Recitationes in Elementa Iuris Civilis (Coimbra, 1817). António Pereira de Figueiredo com Defensio Tentaminis Theologiae (Lisboa, 1770).

E grande o número de pastorais e outros documentos de bispos franceses ligados ao jansenismo e ao galicanismo. 
A biblioteca do Colégio de $\mathrm{S}$. Tomás ao tempo da sua extinção (1834) possuía cerca de 2500 obras. Nela deparamos igualmente com tratados teológicos e canónicos que denotam uma inclinação jansenista e regalista. Eis alguns desses tratados. António Arnauld, Obras (Paris, 1775 e 1783). Pierre Nicole, La Pérpétuité de la Foi (Paris, 1781). Noël Alexandre, Theologia (Veneza, 1769). Justino Febrónio, De Statu Ecclesiae et Legitima Potestate Romani Pontificis, Francoforte, 1772; Lucca, 1768. António Pereira de Figueiredo, De non Definita in Concilio Tridentino... Sufficientia Attritionis, Lisboa, 1776; Id., Anonimi Romani qui de Primatu Papae nuper scripsit Vana Religio et Mala Fides, Lisboa, 1771; Id., Demonstração Teológica, Lisboa, 1769; Tentativa Teológica, Lisboa, 1766; Id., Apêndice à Tentativa Teológica, Lisboa, 1768; Louis Ellies Dupin, Traité de la Puissance Ecclésiastique et Temporelle, 1707; Melchior Leydecker, Historia Jansenismi, Utrecht, 1695. Pietro Tamburini, Introduzione allo Studio della Filosofia Morale, Pavia, 1797. Claude Fleury, Historia Ecclesiastique, Paris, 1769. Noël Alexandre, Theologia Dogmatica, Paris, 1741. Pierre Nicole, Décalogue d'Instructions Théologiques, Paris, 1741. Pierre de Marca, De concordia Sacerdotii et Imperii, Paris, 1704. Jean de Launoy, Opera, Colónia, 1732. Puffendorf, De Officio Hominis et Civis, Francoforte, 1775. Mathias Dannemayer, Institutiones Historiae Ecclesiasticae, Coimbra, 1807. Medicina Theologica, Lisboa, 1794. António Pereira de Figueiredo, Carta do Clero de Liège, Lisboa, 1793; Id., Tentativa Teológica, Lisboa, 1746; Id., Portugueses dos Concílios Gerais, Lisboa, 1787; Id., De Verbo Dei, Lisboa, 1792. Alexandre Noel, Praecepta ad Praedicatores, Veneza, 1731. Antoine Arnauld, Epreuves du Sentiment, Paris, 1785. Dupin, De Antiqua Ecclesiae Disciplina, Veneza, 1770. Berti, Ecclesiasticae Historiae Breviarium. Bassano. 1784. De Suprema Romani Pontificis Auctoritate Ecclesiae Gallicanae, Avinhão, 1747. Van Espen, Iuris Ecclesiasticum, Veneza, 1769; Febrónio, De Statu Ecclesiae, Lucca, 1768.

No Compêndio Histórico do Estado da Universidade (1771) são abonadas várias autotridades nacionais e estrangeiras, como Vernei, Martini, Puffendorf, Thomasius, Bochmero, Heinécio, Van Espen, etc. No cap. II da Parte II, p. 214, tratando-se do Direito Natural e da sua importância, faz-se, por exemplo, uma longa citação de Van Espen. Há que fazer uma distinção nos corpos das leis canónicas entre os cânones que já se encontram derrogados e aqueles que ainda estão em vigor,

«para que depois de serem assim separados uns dos outros se possam os segundos somente haver por abrogados pelo sobredito princípio no caso em que neles concorram as 


\section{Revista de História das Ideias}

circunstâncias necessárias e possam os primeiros conservar sempre a sua autoridade e não possam jamais ter-se por abolidos como fundados em princípios que são de verdade inalterável e eterna»,

lê-se no corpo do texto.

Em nota, vem então uma longa citação tirada da obra de Van Espen, Ius Canonicum, Parte I, Dissert. I «De veterum Canonum et in eis contenta Canonicae Disciplinae stabilitate et legitimo eorum usu». $§ 2$, cui titulis: In Canonibus discernendum, quid iuris naturalis sit, quid positivi:

"Canones quos ad formandos mores, vitia elevanda, atque rite regimen Ecclesiae instituendum jam primi Patres edidere, tametsi frequenter aliquid iuris positivi contineant: ....Quantum ad hoc quod iura illa antiqua continent Ius Naturale abrogari non possunt per contrariam consuetudinem utpote irrationalem. Quantum autem ad hoc quod solum de Iure Positivo continent, possunt esse abrogata: praecipue si dissimulantes hanc contrariam consuetudinem. in quorum potestate est Jus Positivum mutare. intendunt per talem dissimulationem antiqua iura mutare».

$\mathrm{Na}$ Biblioteca do Seminário Maior de Coimbra encontramos várias obras de António Perera de Figueiredo, de Berti e de Cabassut; as Exercitationes ad Pandectas de Bochmer (Hanover, 1764); a Theologia Moralis de Reiffenstuel (Antuérpia, 1743); o Ius Canonicum do mesmo (Veneza, 1743 e 1778); obras de Covarrubias, Fagnanus, Fleuri, Genoveses, Heinécio, Natal Alexandre, Tamburini e Thomassin; o Ius Ecclesiasticum de Schmalzgrueber (Nápoles, 1738); a Theologia Dogmatica et Moralis de Opstraet (Ticino, 1787), as Institutiones de Riegger (Veneza, 1777); o Ius Ecclesiasticum de Van Espen (Lovaina, 1732); e de Febrónio: Ius Publicum Ecclesiasticum (Lisboa, 1772); o De Statu Ecclesiastico (Bulline-Frankfurt, 1763) e o Commentarium in suam retractationem (Francoforte, 1781).

Diremos, em conclusão, que é importante ver a presença das obras de Febrónio e de Van Espen na evolução do pensamento jurídico-canónico para se compreender o posicionamento dos intelectuais e da Igreja. A importância da razão e do direito, a oposição a Roma, a chamada descristianização ou secularização para se entenderem devidamente têm de ter presente ¿ fermentação a nível das inteligências, que vai apontando para c liberalismo, em que Coimbra e a sua Universidade desempenharam um papel de grande relevância. 